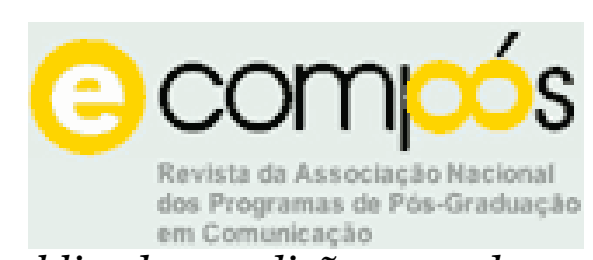

Este artigo foi publicado na edição 1, em dezembro de 2004, da revista eletrônica e-compós: http://www.compos.org.br/e-compos

\title{
MEMÓRIAS GLOBALIZADAS E A CONSTRUÇÃO DOS FUTUROS POSSÍVEIS
}

\author{
Ana Lucia S. Enne ${ }^{1}$
}

UFF

\begin{abstract}
Resumo: A questão da identidade social, principalmente em sua relação com a questão das novas tecnologias, ocupa um lugar central nas sociedades contemporâneas globalizadas. Neste contexto, apresentei minhas reflexões acerca da questão da memória - objeto de disputa de uma rede de agentes e agências sociais na Baixada Fluminense -, em uma perspectiva relacional com a questão da identidade social e cultural e, principalmente, com a utilização das novas tecnologias em rede.

Palavras-chave: mídia; identidade; memória.
\end{abstract}

\begin{abstract}
The question of the social identity, mainly in its relation with the question of the new technologies, occupies a central place in the societies contemporaries. In this context, I presented my reflections concerning the question of the memory - object of dispute of a net of agents and social agencies in Baixada Fluminense -, in a relationary perspective with the question of social identity and cultural e, mainly, with the use of the new technologies in net.
\end{abstract}

Keyword: media; identity; memory.

Resumen: La cuestión de la identidad social, principalmente en su relación con la cuestión de las nuevas tecnologías, ocupa un lugar central en las sociedades contemporáneas. En este contexto, presenté mis reflexiones referentes a la cuestión de la memoria - objeto del conflicto de una red de agentes y de agencias sociales en Baixada Fluminense -, en una perspectiva emparentada con la cuestión de la identidad social y cultural, principalmente, con el uso de las nuevas tecnologías en red.

Palabras-claves: médios; identidad; memoria.

Resumée: La question de l'identité sociale, principalement en sa relation avec la question des nouvelles technologies, occupe une fonction centrale dans les sociétés contemporains. Dans de ce contexte, j'ai présenté mes réflexions au sujet de la question de la mémoire - objet de conflit d'un filet

\footnotetext{
${ }^{1}$ Graduada em Comunicação Social pela PUC/RJ, Mestre e Doutora em Antropologia Social pelo PPGAS/Museu Nacional/UFRJ. Bolsista recém-doutora pelo PRODOC/CAPES no Programa de PósGraduação em Comunicação da Universidade Federal Fluminense/UFF, onde coordena o Laboratório de Mídia e Identidade (LAMI).
} 
les agents et les agences sociales dans Baixada Fluminense -, dans une perspective apparentée avec la question l'identité sociale et culturel, principalement, avec l'utilisation des nouvelles technologies dans le filet.

Mots-clé: médias; identité; mémoire.

Muitos autores têm se voltado para entender as transformações na chamada "sociedade pós-moderna”, em que ideais caros ao racionalismo moderno vão sendo desconstruídos. Novas tecnologias se colocam a serviço de um mundo em crescente interação, em que as fronteiras constituídas cedem espaço para mercados comuns, rede mundial de computadores, expansão dos mecanismos comunicacionais, redimensionamento dos Estados nacionais, internacionalização de padrões culturais, entre outras conseqüências celebradas da nova ordem globalizada. Mas o mundo das culturas sem fronteiras também é o espaço das exclusões sociais de matizes diversos. Como descreve Z. Bauman, turistas e vagabundos são as duas faces de um mesmo sistema, que premia os que se agregam à sociedade de consumo mas martiriza os que dela são excluídos. ${ }^{2}$ Visões otimistas, como o libelo pró-cibercultura de Pierre Levy, 3 encontram oponentes radicais na figura dos desencantados com a sociedade da informação, como o próprio Bauman. Novos "apocalípticos" e "integrados" se digladiam em uma nova arena de disputas. Outros arriscam palpites temperados, como a previsão otimista de Milton Santos de que seria possível uma sociedade que utilizasse os melhores recursos tecnológicos já criados pelo homem em um mundo em que o ser humano e a vida fossem os parâmetros éticos a orientar as condutas, em detrimento do mercado. 4

Independentemente da vertente, em todas as análises acima citadas e em tantas outras a questão da identidade social nas sociedades contemporâneas, principalmente em suas relação com a questão das novas tecnologias, ocupa um lugar central. Nesse contexto, procurei situar parte de minhas reflexões acerca da questão da memória - objeto de disputa de uma rede de agentes e agências sociais - na Baixada Fluminense, ${ }^{5}$ procurando pensá-la em uma perspectiva relacional

\footnotetext{
${ }^{2}$ BAUMAN, 1999.

${ }^{3}$ LEVY, 1999.

${ }^{4}$ SANTOS, 2000.

${ }^{5}$ Tais reflexões encontram-se em minha tese de Doutorado em Antropologia Social, “Lugar, meu amigo, é minha Baixada": memória, representações sociais e identidade na Baixada Fluminense, orientada pelo prof. Doutor Antonio Carlos de Souza Lima e defendida no PPGAS/Museu Nacional/UFRJ em outubro de 2002. A
} 
com a questão da identidade social e cultural. Como também têm apontando diversos autores, estaríamos assistindo a um "boom da memória" neste fim e princípio de século, em que a perda de referências tradicionais acionaria uma preocupação hiperbólica com a preservação do passado e mesmo com a sua reinvenção, no sentido proposto por Anderson, entre outros. ${ }^{6}$

Trata-se, sem dúvida, de um mundo em transformação, marcado pelas indefinições.7 Nesse sentido, determinados atores sociais e suas agências, que há cerca de uma década desempenhavam papéis destacados na configuração das sociedades, foram perdendo espaço e se enfraquecendo. Neste caso, e pensando especificamente na região da Baixada Fluminense, podemos enquadrar as associações de moradores, as casas de cultura, a imprensa regional e os movimentos sociais, que ocupavam local de destaque dentro da ordem social local, agências privilegiadas das mudanças operadas. No entanto, tais agências perderam força e foram deslocadas do eixo protagonista. Os movimentos sociais, na Baixada, por exemplo, não têm hoje a vitalidade com que floresceram nos anos 80. Das muitas casas de cultura inauguradas no mesmo período, poucas sobreviveram, mesmo assim com uma influência, dentro da ordem atual, bem menor, se comparada com a exercida na década citada. Elas não são hoje uma referência fundamental na produção de identidades sociais na região, embora continuem, em alguns casos, atuantes.

Atualmente, outros agentes e agências passaram a desempenhar os papéis antes reservados a elas. Nesse bojo, podemos citar aqueles ligados à rede de memória e história na Baixada, objeto de pesquisa em minha tese de doutorado. Mas é preciso listar ainda as Organizações não-governamentais (ONGs), os

relação entre memória/identidade na Baixada Fluminense e as tecnologias midiáticas é objeto do projeto de pesquisa "Imagens da Baixada", que está sendo desenvolvido desde maio/2003, no Programa de PósGraduação em Comunicação da Universidade Federal Fluminense/UFF, sob a orientação da prof. ${ }^{a}$ Marialva Carlos Barbosa, dentro do programa de bolsas PRODOC/CAPES.

${ }^{6}$ Cf. ANDERSON (1985). Sobre a relação entre memória e mídia, ver HUYSSEN (2000) e BARBOSA (2001).

${ }^{7}$ É preciso tomar cuidado, ao pensarmos as mudanças nas sociedades contemporâneas, com uma tendência comum em muitos autores de hipervalorizar as transformações na "pós-modernidade", desconsiderando o processo histórico e outros muitos contextos e épocas marcadas por rupturas e continuidades nas identidades sociais e culturais. Dessa forma, estamos pensando aqui as desconstruções dos conceitos de identidade nas sociedades recentes como características desta época (em especial suas imbricações com as mudanças nas tecnologias e na ação dos meios de comunicação) e não como um "fenômeno único" da "pós-modernidade". 
movimentos ecológicos e os projetos ligados à expansão turística, todos exercendo hoje, na Baixada, papel proeminente, envolvendo verbas e dotações de órgãos públicos e particulares e também fundamentais na construção de identidades sociais e culturais. Neste sentido, podemos pensar as propostas de transformações sociais na Baixada Fluminense como inseridas dentro de uma pauta extra-local, já que estas são agências que vêm desempenhando papel de destaque nas sociedades globalizadas de forma geral. Sem dúvida, uma reflexão mais ampla sobre tal processo deveria abarcar tais agentes e agências, que foram ganhando força no decorrer da década de 90, além de se propor a mapear os já citados expoentes dos anos 80 .

Apontados alguns dos desdobramentos possíveis para futuras pesquisas, voltemos ao que foi, de fato, objeto de reflexão preliminar: a ação de agentes e agências voltados para "resgatar" o passado da região. Foi isso o que procurei demonstrar, no decorrer da tese, como sendo vital para a construção de identidades pessoais e sociais. Dessa forma, o passado, como um recurso disputado pelos agentes diversos encontrados na pesquisa de campo, funciona como o suporte para apropriações do presente. É em cima de demandas deste último que se oferecem versões desse passado. Mas acredito que, na verdade, o que deve ser pensado é a construção dos futuros possíveis. Pois, claramente, todo o esforço empreendido no sentido de "resgatar", contestar ou reinventar o passado, a partir das necessidades do presente, visa sempre postular possibilidades de futuros. Quando se perguntam acerca do que teria sido a Baixada Fluminense para dar conta de uma perda de imagens positivas para a Baixada do presente, os agentes envolvidos com esse processo estão pensando fortemente em que Baixada almejam construir. O passado é objeto de disputas, o presente é arena de identidades fluidas e muitas vezes angustiantes. E o futuro? A memória do passado reinventado não seria exatamente, em um sentido inverso, uma memória de um futuro desejado? Ao contrário do que se apresenta, não seria o devir o objetivo maior do projeto de produção de identidades na Baixada, e não o passado e nem mesmo o presente?8

\footnotetext{
${ }^{8}$ Neste sentido, podemos citar Charles Taylor: "from a sense of what we have became, among a range of present possibilities, we project our future being”. TAYLOR, 1989, p. 47. Ele se refere, no caso da construção do self, à remissão à infância como estratégia narrativa. Nesse sentido, podemos pensar o passado da Baixada
} 
Se entendemos e partilhamos das concepções apresentadas, de que o que se entende por comunidade e identidade são construções simbólicas, resultantes de interações e conflitos, e não realidades dadas e cristalizadas, algumas questões foram colocadas no decorrer de minha pesquisa: de quantas Baixadas e de que Baixadas estão falando todos? Acredito que essa é a questão que permeia a rede de memória e história na Baixada. Na verdade, tais perguntas poderiam ser feitas para tantos outros objetos de estudo, em especial comunidades regionais, visto o caráter de desterritorialização das sociedades inseridas no processo de globalização. ${ }^{9} \mathrm{O}$ que seria específico no caso da BF, a meu ver, seria a relação entre essa rede de memória e história e a produção de "imagens positivas", gerando identidades que se contrapusessem a uma identidade "estigmatizada", veiculada principalmente pela imprensa carioca, com a qual os moradores da região vêm se defrontando há décadas.

Porém, tais questões se ampliaram a partir de determinados contextos históricos, na minha concepção associados à expansão da rede em meados dos anos 90. Assim, como podemos pensar a Baixada Fluminense em uma sociedade marcada por valores globais, entre eles a fluidez das fronteiras e das identidades? Se estamos falando de discursos construídos, como pensá-los dentro de uma sociedade marcada exatamente pelo apogeu da informação? E, finalmente, se estamos falando na utilização de memórias coletivas como ponto de ancoragem para identidades, torna-se vital pensar o tempo como conceito e como realidade vivida, principalmente com a fragmentação das noções clássicas de tempo e espaço. ${ }^{10}$

como "a infância" no sentido formador da identidade. E o futuro, mesmo para o indivíduo, ultrapassa sua própria vida e se transforma em legado (p.51). Mais uma vez, evidencia-se aqui a importância da narrativa como gênero privilegiado para a construção de imagens e identidades.

${ }^{9}$ IANNI, 1993.

${ }^{10}$ Muitos autores têm pensado a categoria tempo em suas múltiplas apropriações culturais. Ver, entre outros, BOSI, Alfredo. "O tempo e os tempos". In: SOARES, A. (org.). Tempo e História. São Paulo, Companhia das Letras: Secretaria Municipal de Cultura, 1994, especialmente sua conceituação acerca do tempo reversível (exatamente o que pode ser reconstruído pela memória), cf. p. 28. Ver também ELIAS, Norbert. Sobre o Tempo. Rio de Janeiro, Zahar, 1998, MUNN, Nancy. "The Cultural Anthropology of Time: a critical essay". In: Annual Review of Anthropolgy, 21, 1992, pp. 93-123, POCOCK, David. "The anthropology of timereckoning". In: MIDDLETON, J. (ed.) Myth and Cosmos. New York, The Natural History Press, 1967, BOURDIEU, Pierre. "The attitude of the Algerian peasant toward time". In: PITT-RIVERS, J. Mediterranean Countrymen. Paris, Mouton \& Com, 1983, LEACH, E. "Dois ensaios a respeito da representação simbólica 
O processo de globalização vem sugerindo novas interpretações para a questão do tempo e do espaço, em que estes estariam marcados pela velocidade das transformações e por uma intensa mobilidade de fronteiras e marcos. Se a identidade, por si só, já se constrói nos fluxos e nas interações, como um processo, no mundo globalizado, em que o tempo e o espaço, em suas dimensões tradicionais, teriam sido substituídos por versões atualizadas marcadas pela mutabilidade, como se constróem identidades com algum grau de permanência? As novas relações entre o local e o global parecem apontar para uma compressão das visões acerca dos paradigmas vigentes, criando outras concepções e oferecendo outras possibilidades de construção do futuro. Como pensar a memória local a partir de uma sociedade globalizada? Podemos perceber, nas práticas discursivas locais, preocupações com a construção de uma memória coletiva que remete ao local, à própria Baixada, mas também ao global, uma memória coletiva que remete a outros movimentos e correntes transnacionais e transculturais.

Alguns dos agentes sociais que, no trabalho de resgate do passado, renegam a construção da imagem da Baixada Fluminense via imprensa e também não se identificam, a partir de sua identidade como "acadêmicos", com a memória coletiva que constrói uma visão glamourizada do passado, estão marcando, pela ruptura, um novo mito memorialístico, onde a adesão da coletividade não se dá no local, no regional, mas no global, em todas as tradições de resistência e construção memórias de novas etnicidades. Mas, ao mesmo tempo, quando convergem com agentes antagônicos, no sentido de produzirem imagens românticas desse mesmo passado de forma a cobrir de positividade o presente, não é o local que se sobrepõe novamente, com suas demandas próprias e inerentes?

Assim, o que se coloca, embora ainda de maneira pouco explorada no plano do discurso dos próprios agentes, é a necessidade de pensar o local, a partir das transformações no âmbito global. Mas mesmo que ainda não transformada em projeto deliberado, não resta dúvida, a meu ver, que existe uma intensa relação entre as mudanças operadas na rede de memória e história da Baixada Fluminense na última década e as transformações nos eixos local/global. Na perda

do tempo". In: Repensando a Antropologia. São Paulo, Perspectiva, s/d e FRIEDMAN, Jonathan. "Our time, their time, world time: the transformation of Temporal Modes". In: Ethnos, vol. 50, III-IV, 1985. 
dos paradigmas da antiga ordem, novos medos se desenham, como a preocupação em não se perder os aromas e sabores da sua "própria" história e memória. Em um mundo de sentidos múltiplos, também se multiplicam as possibilidades de construção de memórias sociais. Por isso, ancorá-las em registros do passado local também funciona como alicerce para a manutenção de identidades onde essas se apresentem como ameaçadas pela desconstrução.

Neste sentido, também, podemos entender o crescimento, nos últimos anos, de estudos de história local e regional, recuperando uma tradição da História Nova que havia sido relegada a um plano menor dentro da historiografia contemporânea. O medo de incorrer na chamada "micro-história", com perda dos grandes temas e universos de uma história nacional ou universal, fez por um longo período que os objetos relacionados à história local fossem preteridos. No entanto, a preocupação em pensar o local frente às intervenções e transformações globais devolveu à história regional um papel de proeminência dentro dos estudos historiográficos. Nesse movimento, a história da Baixada Fluminense, regional por definição (embora com temáticas que a ultrapassem) começou a ser praticada mais intensamente pelos meios universitários, internos e externos à região, e sendo cada vez mais aceita dentro dos círculos mais amplos das universidades brasileiras.

Mesmo, porém, com todo o esforço para ancorar as identidades em termos locais antes que elas se dissolvam, não resta dúvida de que nos dias atuais já não há como separá-la da polifonia da ordem global, adquirida através de uma sociedade em rede, como descreve Castells, em que os meios de comunicação universalizam culturas e memórias. ${ }^{11}$ Les Back, em seu trabalho sobre as novas etnicidades em Londres, ${ }^{12}$ aponta para este caráter de adesão da memória de grupos locais com diásporas transnacionais, uma remissão a um elo antes perdido e agora reencontrado com um grupo de origem, especialmente ancestrais, que podem ser revividos e mesmo transformados (via absorção e readaptação a partir dos traços locais, razão pela qual Les Back utiliza a noção de rizoma proposta por Guattari e Deleuze), mas, que no fundo, permitem a criação de uma memória original e global. Canclini aborda esta questão quando fala do multiculturalismo e da

\footnotetext{
${ }^{11}$ CASTELLS, 1992.

${ }^{12}$ BACK, 1996.
} 
constituição de culturas híbridas, ${ }^{13}$ que celebram a interpenetração das culturas locais com traços que lhes são exteriores, resultando em novas apropriações e novas formas culturais. A mesma idéia está contida em Ulf Hannerz, ${ }^{14}$ que aposta na idéia de fluxos culturais como explicação para este movimento típico da nova ordem mundial, onde a flexibilização das fronteiras postula novas identidades e exige um reexame das noções de tempo e espaço, o que vem sendo feito, de maneiras diversas, pelos próprios agentes sociais.

Alain Touraine apontou para a existência de um "timeless time", um tempo onde diversos grupos se encontram fora das dimensões do tempo social, comprimido pelas redes de relação global. ${ }^{15}$ Estes grupos, fora do tempo, poderiam desempenhar papéis de agentes sociais na construção de seus futuros, ou estariam confinados a circularem em áreas de exclusão, onde o tempo social seria marcado por outros referenciais? O sociólogo defende que é possível para categorias excluídas desempenharem tais papéis desde que consigam condições propícias, razão pela qual torna-se fundamental a atuação de ONGs e outras instituições. Elas devolveriam aos agentes as condições de construção deste futuro, muitas vezes pela construção de uma memória e de uma identidade coletiva.

As redes de uma sociedade globalizada aparecem como elementos compressores das dimensões tradicionais do tempo e do espaço. Assim, a apropriação deste passado via meios de comunicação de massa, um passado que esvai o presente e prepara condições para a projeção do futuro, parece ser um elemento interessante para pensar a ação dos agentes sociais que encontrei na Baixada, reunidos nas mais diversas agências. Assim como o tempo estaria sendo comprimido no mundo globalizado, as noções relacionadas ao espaço também não escapariam desta compressão. Kevin Hetherington ${ }^{16}$ propõe a substituição dos mapas cartográficos de inspiração cartesiana e euclidiana por outros, múltiplos e fragmentados, onde a idéia de redes, fluxos e interações estejam todo tempo presente. A própria idéia de região deveria ser questionada. Neste sentido, a

\footnotetext{
${ }^{13}$ CANCLINI, 1994 e 1998.

${ }^{14}$ HANNERZ, 1992.

15 "A mestiçagem do tempo", na Conferência "A Construção do Tempo e os futuros possíveis", realizada na Universidade Cândido Mendes, maio de 1999.
} 
imagem proposta é a do espaço em branco, marcado pela catástrofe e pela entropia, onde tudo adquire sentido a partir da interação, e não a partir de sentidos dados. As fronteiras antes postuladas são comprimidas, mas, para o autor, não cessam de existir fronteiras, elas são reatualizadas nos fluxos e interações.

Assim, o passado poderia ser pensado não só como marco para a construção do presente, mas como fundação de um futuro que se deseja construir. Neste sentido, podemos pensar o esforço em monumentalizar esse passado, seja através da construção de museus, casas de memória, institutos históricos e outras agências, ou pela luta pela preservação de registros arquitetônicos e culturais, como igrejas, torres, sedes de fazendas, ruínas e outros "aromas" e "sabores" que marquem o encontro com a memória que não se quer perdida. ${ }^{17}$ Tal esforço, inclusive, extrapolaria a atuação dos próprios agentes e agências descritos como pertencentes à rede de história e memória, e mobilizariam as autoridades públicas, também empenhadas em fixar os monumentos/marcos do novo sentido a ser conferido ao local, conjugando modernidade e tradição, recorrendo a vestígios arquitetônicos, naturais e culturais, quando existentes, ou tratando de inventá-los. Neste sentido, a preocupação com a identidade pode ser relacionada à delimitação de políticas públicas.

Dessa forma, acredito que as transformações gerais por que vem passando a região da Baixada, sendo incorporada na rede global de consumo como mercado promissor, vivenciando transformações em termos de projeção de "imagens positivas”, inclusive pela atuação dos mandatários da política regional, ou seja, todo o processo percebido, embora ainda iniciante, de inserção da região em uma ordem econômica e social da qual sempre esteve excluída, não pela via da cidadania mas pela mão do consumo, também tenderão a produzir mudanças na composição da rede de memória e história na Baixada, acelerando seu tempo de articulações, alianças e rompimentos, bem como vencendo barreiras espaciais e inserindo-as em contextos mais amplos do que os até então desenhados. Não só

\footnotetext{
16 "Onde está o mundo? A presença e a ausência do Globo", na Conferência "A Construção do Tempo e os futuros possíveis", realizada na Universidade Cândido Mendes, maio de 1999.

17 Sobre a monumentalização da memória, ver também HANDLER, Richard. "On Sociocultural Discontinuity: Nationalism and Cultural Objectification in Quebec”. In: Current Anthropology. Vol. 25, n 1 ,
} 
pelas inserções nas redes "acadêmicas", ou pelas "parcerias" montadas com agentes e agências externos à Baixada (como órgãos públicos, ONGs, fundações, entre outros), mas também pela utilização de ferramentas de visibilidade em escala global, como a Internet. Nesse sentido, o surgimento de sites sobre a Baixada cria novas possibilidades de interação, e colocam a disputa pelo passado em outro âmbito, para além da local.

As novas tecnologias poderão, com a sua introdução cada vez mais acentuada no âmbito das realidades regionais, como no caso da Baixada Fluminense, funcionar como pontes fundamentais nessa imbricação dos tempos passado, presente e futuro. Pensando a manutenção do passado como estratégia política de atores posicionados no presente, que transformam a memória em conflito e disputa por poder e controle de recurso materiais e simbólicos, não podemos perder de vista que a noção de projeto político acompanha diretamente este trabalho de reelaboração das lembranças e dos esquecimentos. Porém, no caso estudado, as demandas do presente, que norteiam e enviesam os olhares sobre o passado, são também demandas de futuros possíveis, em que se buscam construir identidades positivas e inserções na nova ordem mundial. A mídia tradicional, em especial a grande imprensa carioca, que veio construindo ao longo de meio século um imaginário estigmatizante e negativo sobre a Baixada, já vem indicando mudanças neste enfoque. ${ }^{18}$ Mas as visões preconceituosas acerca da região ainda estão arraigadas, segundo percebem os agentes entrevistados, no senso comum, especialmente aquelas ligadas à violência e ao descaso público. Neste embate de representações, a utilização de mídias alternativas (tentadas anteriormente com rádios e tevês comunitárias, como a TV Maxambomba, de Nova Iguaçu, bem como com a publicação de jornais locais) se constitui em estratégia fundamental de enfrentamento e reinvenção do passado e do presente.

No entanto, se as mídias alternativas convencionais, tanto impressa quanto eletrônica, demonstraram um poder de fogo minimizado frente ao poderio esmagador da grande mídia, a internet tem sido pensada como um novo front de 
construção de imaginários, principalmente graças ao seu alcance para além das dimensões e limites territoriais da própria Baixada. Exatamente por essa razão, vários agentes e agências que estão envolvidos com a questão da memória e da identidade na região têm colocado a inserção na rede mundial de computadores, seja para troca de e-mails ou para a criação de sites, como uma preocupação prioritária nas estratégias de atuação. As tecnologias da informação são pensadas, portanto, como ferramentas básicas na disputa pelas construções e desconstruções de identidades sociais e culturais, permitindo que agentes e agências de menor visibilidade nas grandes mídias ocupem espaços e consigam maior visibilidade e expansão vocal. Neste sentido, as novas tecnologias podem, em médio prazo, equilibrar o jogo das representações midiáticas entre emissores e receptores tradicionais, criando uma rede de múltiplas emissões e recepções, fazendo com que a construção de futuros possíveis se transforme na projeção de futuros prováveis, em que a ação de tais atores sociais tenha de fato implicações mais decisivas nos projetos políticos, culturais e sociais para a região.

\footnotetext{
${ }^{18}$ Sobre este ponto, conferir o artigo "Do 'Faroeste Fluminense' ao 'Futuro que já chegou': as representações da grande imprensa carioca acerca da Baixada Fluminense”, apresentado por mim no Intercom 2003.
} 
e-compós: http://www.compos.org.br/e-compos

\section{BIBLIOGRAFIA:}

BACK, Les. New ethnicities and urban culture. Racisms and multiculture in young lives. New York, St. Martin's Press, 1996.

BARBOSA, Marialva. "Medios de Comunicación y Conmemoriaciones. Estratégias de Reactualización y Construcción de la memória”. In: Comunicación, Historia y Memoria. Itinerarios para pensar el presente, $\mathrm{n}^{\circ}$ 39, vol. XX, 2001.

BAUMAN, Z. Globalização, as conseqüências humanas. RJ, Jorge Zahar, 1999.

CANCLINI, Nestor. Culturas híbridas. SP, Edusp, 1998. - Museos, aeropuertos y ventas de garage (las identidades culturales en un tiempo de desterritorialización. In FONSECA, Cláudia (org.). Fronteiras da Cultura, Horizontes e Territórios da Antropologia na América Latina. Porto Alegre, Editora da Universidade Federal do RS, 1994.

CASTELLS, Manuel. A Era da Informação: Economia, Sociedade e Cultura. O poder da Identidade. Volume 2. São Paulo, Paz e Terra, 1992.

HALL, Stuart. A identidade cultural na Pós-Modernidade. Rio de Janeiro, DP\&A Editora, 1997.

. "Cultural Identity and Diaspora". In: RUTHERFORD, Jonathan. Identity. Community. Culture. Difference. London, Lawrence \& Wishart, 1990.

HANNERZ, Ulf. Cultural Complexity. Columbia University Press. New York, 1992.

HUYSSEN, Andreas. Seduzidos pela Memória. Rio de Janeiro, Aeroplano Editora, Universidade Cândido Mendes, Museu de Arte Moderna-RJ, 2000.

IANNI, Octávio. A Sociedade Global. Rio de Janeiro, Civilização Brasileira, 1993.

LEVY, Pierre. Cibercultura. São Paulo, Editora 34, 1999.

SANTOS, Milton. Por uma outra globalização. Rio de Janeiro, Record, 2000.

TAYLOR, Charles. Sources of the Self. The Making of the Modern Identity. Great Britain, Cambridge University Press, 1989. 